\title{
LAVA DOME CHANGES DETECTION AT AGUNG MOUNTAIN DURING HIGH LEVEL OF VOLCANIC ACTIVITY USING UAV PHOTOGRAMMETRY
}

\author{
Ruli Andaru ${ }^{1}$, Jiann-Yeou Rau ${ }^{2}$ \\ ${ }^{1}$ Department of Geomatics, National Cheng Kung University, Taiwan - ruliandaru@ugm.ac.id \\ Department of Geodetic Engineering, Gadjah Mada University, Indonesia \\ ${ }^{2}$ Department of Geomatics, National Cheng Kung University, Taiwan - jyrau@geomatics.ncku.edu.tw
}

KEY WORDS: lava dome, changes detection, UAV, volcanic activity, photogrammetry

\begin{abstract}
:
Lava dome changes detection during increasingly high volcanic activity are essential for hazard assessment purposes. However, it is challenging to conduct direct field measurement due to safety reason. Here, we investigate the lava dome changes of Mount Agung in Indonesia during the highest level of volcanic activity. On 22 September 2017, the rumbling and seismic activity in this volcano started increasing to the highest level for a period of time. We afterwards collected image data at lava dome area by using UAV over this time period. To accomplish the goal of change detection, we assembled and developed a fixed-wing UAV platform, i.e. Buffalo FX-79 to acquire images of Mount Agung whose elevation is roughly 3,142 $\mathrm{m}$ above sea level. We acquired the UAV images on two dates, i.e. Oct 19 and Oct 21 of 2017. Due to an exclusion zone surround the volcano, we could only operate the UAV at $20 \mathrm{~km}$ distance from the crater. With these data set, we produced three-dimensional point clouds, high-resolution Digital Elevation Model and orthophoto by using Structure from Motion (SfM) and Multi View Stereo (SfM-MVS) technique with Photoscan Pro software. From orthophoto data, we found two fluid areas at the crater's surface in NE direction $(4,375.9 \mathrm{sq}-\mathrm{m})$ and SE direction $(3,749.8 \mathrm{sq}-\mathrm{m})$. We also detected a fumarole which emitted steam and gases in the eastern part that continued for several days. In order to reveal the changes in lava dome surface, we used DEM to create cross-section profile. After that, we applied cloud to cloud comparison (C2C) algorithm to calculate the difference of lava dome based on two data set of point clouds and compared it with interferometric result from Sentinel-1A data. The data from the Sentinel-1A satellite (15 Oct - 27 Oct 2017) were processed to obtain the interferogram image of Mount Agung. This research therefore demonstrates a potential method to detect lava dome changes during high level of volcanic activity with photogrammetric methods by using UAV images. Within only two days the data were successfully acquired. From the DEM data and cross-section profile between two data set, we noticed that no significant surface change was found around the lava dome surface. Moreover, we also found that there was no significant lava dome changes and vertical displacement during these two time periods as the point cloud comparison and distance result. The average of difference distance is $2.27 \mathrm{~cm}$ with a maximal and minimal displacement of $255 \mathrm{~cm}$ and $0.37 \mathrm{~cm}$ respectively. This result was then validated by using InSAR Sentinel that showed small displacement, i.e 6.88 $\mathrm{cm}$. It indicated that UAV photogrammetry showed a good performance to detect surface changes in centimeter fraction.
\end{abstract}

\section{INTRODUCTION}

Lava domes were mounds of viscous lava and rocks that are piled up around a volcanic vent. They formed as magma cools and degases relatively quickly after erupting onto the Earth's surface (Calder, et al., 2015). Lava dome eruptions are unpredictable hazardous volcanic phenomena, so that it is necessary to detect the changes periodically in the form of morphology, shape and visual surface. It becomes crucial especially when the volcanic activity level goes up. The detection of surface changes that occur in the lava dome is thus important for hazard assessment purposes. However, it is challenging to conduct direct field measurement during the alerting volcanic activity due to safety reason. Therefore, an alternative method is needed that is capable of measuring the changes with sufficient accuracy safely and efficiently. In order to do this, there are actually many key methods for monitoring changes detection in active lava dome, i.e: terrestrial observation, aerial or satellite imagery. Considering these alternatives, we ultimately investigate the lava dome changes of Mount Agung in Indonesia during the highest level of volcanic activity by using UAV photogrammetry.

Photogrammetric techniques had been successfully applied to detect lava dome changes of Mount St. Helens by Major et al. (2009) by using oblique terrestrial images from a network of remotely placed cameras. In addition, UAV platform had successfully performed and represented a promising technique for acquiring high resolution topographic and imaging information of Mount Merapi's lava dome as done by Dharmawan et al. (2013). Furthermore, UAVs had already been successfully exploited during an eruptive crisis employed to lava flow monitoring for risk mitigation and civil protection (Beni, et al., 2019).

On 22 September 2017, in Mount Agung (Bali, Indonesia), the frequency of rumbling and seismic activity increased around the volcano that made the alert status to the highest level (PVMBG, 2017). Since then, the Indonesian National Disaster Management Authority declared a $12 \mathrm{~km}$ exclusion zone surround the volcano. This alert status lasted for a month and decreased significantly by the end of October 2017. After that, on 21 November, it increased again. Finally, 4 days later, a magmatic eruption began, after more than 2 months of seismic rumbling that had led authorities to evacuate more than 100,000 residents from the exclusion zone ringing the mountain on Bali Island. During the volcanic activity, we needed to monitor and detect the phenomena in the lava dome surface, since its changes indicated that magma chamber swelled. By knowing the pattern of changes at lava dome from several times, it will be greatly useful for hazard assessment purposes. With UAV, it can predict the lava flow path for active crisis management operations as done by Turner, et al. (2017).

This research mainly has two aims. Firstly, the image at the lava dome is collected by using UAV platform during high volcanic 
activity. The second aim is to analyse the lava dome changes between two UAV data set and compare with Sentinel 1A data. To accomplish the first aim, we assemble and develop a fixedwing UAV platform, i.e. Buffalo FX-79 as shown in Figure 1 to acquire images of Mount Agung with an elevation of 3,142 m above sea level.
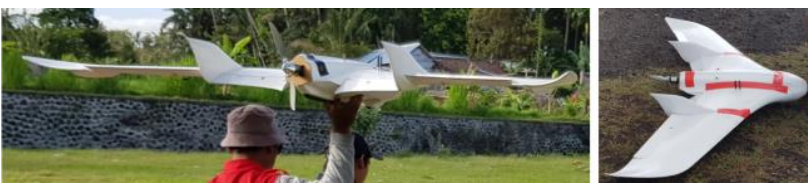

Figure 1. UAV Fixed wing, Buffalo FX-79 with 2,000mm wingspan length, $1,270 \mathrm{~mm}$ fuselage length, flying weight $5000 \mathrm{gr}$, flight speed $70 \mathrm{~km} /$ hours and $100 \mathrm{~km}$ flight distance.

We acquired the UAV images on two dates during highest level volcanic activity, which were Oct 19 and Oct 21 of 2017. In order to analyse the surface changes at lava dome, we generate highresolution DEMs and orthophoto by the acquired UAV imagery on these dates. The rapid mapping of high resolution Digital Elevation Model (DEM) and topographic data were essential for monitoring and forecasting lava flow behaviour during the effusive crises. DEM and orthophoto, as the primary data, were used to estimate lava dome changes analysis and further derive lava flow paths for hazard assessments purposes.

\section{DATA AND METHODS}

\subsection{Study Area}

The study area is located in Mount Agung, one of active volcanoes in Indonesia. It is the highest point on Bali island, with an elevation of 3,142m (Figure 2). Historical records show that in 1963, Mount Agung's eruption was one of the largest volcanic eruptions of the 20th Century, being at rate VEI 5. In 2018, it erupted again after two months of high seismic activity. These data collection was conducted in October 2017, one month before eruption.

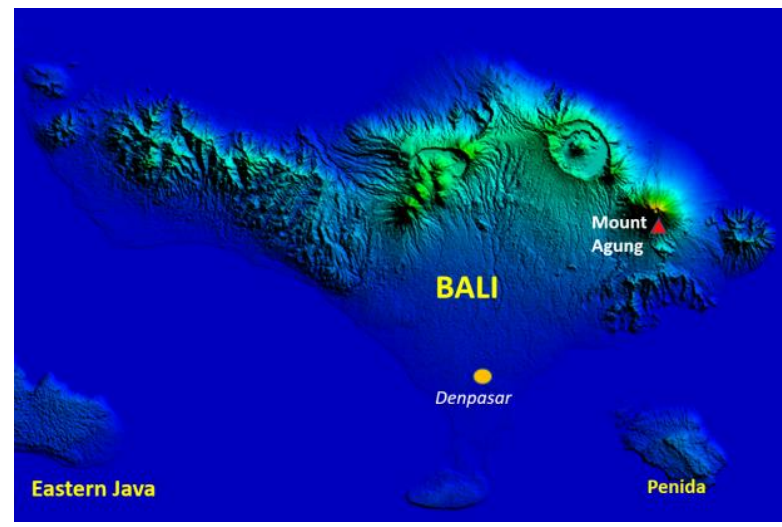

Figure 2. Location of Mount Agung, Bali, Indonesia

\subsection{UAV technical flight}

Due to an exclusion zone is surrounding the volcano with $12 \mathrm{~km}$ during the highest volcanic activity, we operated UAV in a distance of $20 \mathrm{~km}$ from the crater to carry out the mission (Figure 3). We modified Buffalo FX-75 powered speed and battery capacity to be able to fly at an altitude above the summit (above $3,500 \mathrm{~m}$ ), so it could fly for more than 1.5 hour. The main challenge associated with UAV acquisition in the active volcano was the environmental parameters, such as wind turbulence, fumarole activity, cloud coverage and high altitude. This would likely cause flight instability and damage the UAV platform during the mission. To acquire the image in Mount Agung's crater, which had $1 \mathrm{~km}$ in diameter, we created 2 flight lines with $800 \mathrm{~m}$ height above the summit (as shown in yellow line colour). Because our flight plan altitude was $4,000 \mathrm{~m}$, we had to divide our mission into 2 steps; pre-flight altitude mission (PFAM) and flight mission (FM). PFAM is a flight around take-off area with a certain ascending degree to reach the required altitude (indicated in red area), whereas FM is a real mission to acquire the summit area (indicated in white area).

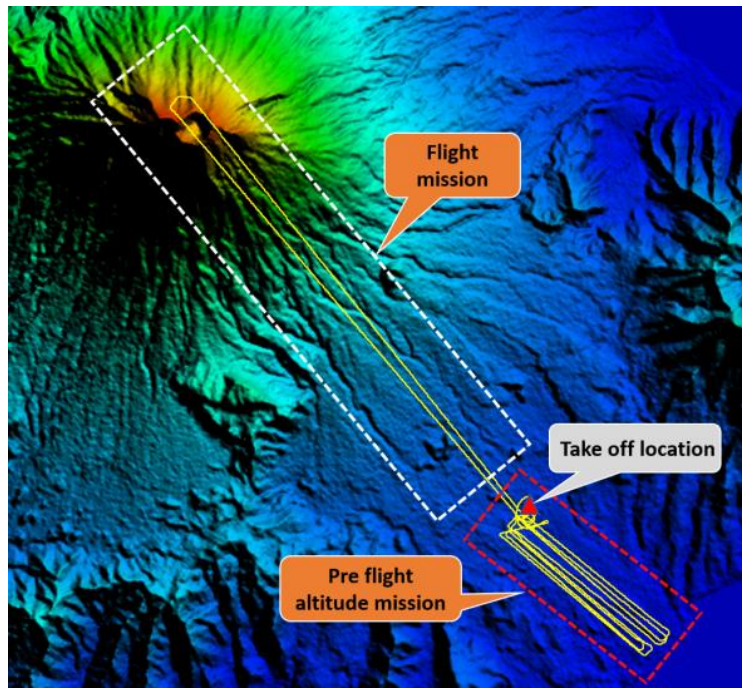

Figure 3. Flight plan and take-off location.

Red colour area indicated pre-flight altitude mission.

On Oct 19, we conducted two flights. On the first flight, we carried out PFAM whose distance was $10 \mathrm{~km}$ long with a certain ascending slope to reach 2,000 $\mathrm{m}$ altitude and then performed flight mission to acquire crater area (Figure 4). Unfortunately, this strategy was failed and the UAV crashed due to extreme wind turbulence when ascending and reaching a height of 2,900 $\mathrm{m}$.

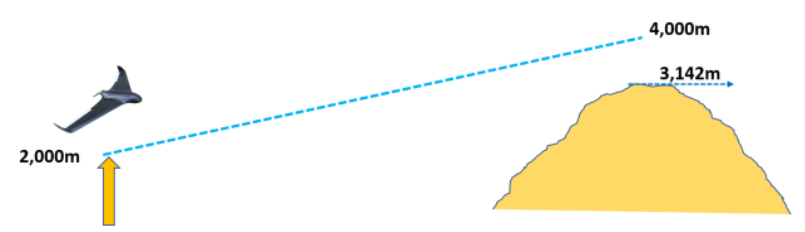

Figure 4. First strategy to flight mission

On the second flight, we changed the flight strategy by performing PFAM within $20 \mathrm{~km}$ to reach a height of $4,000 \mathrm{~m}$ and then made it fly to the crater with same altitude (Figure 5). It turned out that the UAVs were fortunately more stable in the crater because they did not need high power to climb even against the strong wind. However, this condition caused inconsistent spatial resolution due to varied photo distance at the mountain slope.

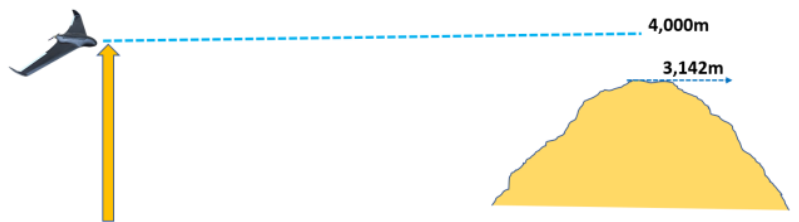

Figure 5. Second flight mission strategy

This strategy had successfully acquired more than 535 images that covers about 56 sq-km of the volcano's summit area with 75 
minutes of flight duration. Two days later, Oct 21, we conducted another mission with the same flight plan. In order to get higher spatial resolution image, the flight altitude was reduced to $3,700 \mathrm{~m}$ and it was successful to capture the crater aerially.

\subsection{UAV photogrammetric data}

The UAV carried Sony RX100 digital camera during the mission (19 and 21 Oct 2017). We got more than 500 images on each mission, but only 160 of which covered the crater area to be processed later. Two high-resolution UAV surveys were performed on the lava dome of Mt. Agung. The first data set was acquired in 19 Oct with 4,000m a.s.l (above sea level) and obtained a spatial resolution of $44.7 \mathrm{~cm} / \mathrm{px}$. The second data set was acquired in 21 Oct with 3,700 a.s.l and obtained a spatial resolution of $33.3 \mathrm{~cm} / \mathrm{px}$. Since we had no chance to acquire the GPS field data for ground control at the surrounding area of volcano, the images were captured and geotagged by using an internal GPS. We used this position data as geo-reference on this research. In order to co-register these two data set, we marked several registration control points between two data set. In which, the first date's data, i.e. 19 Oct, is treated as reference one. After performing registration of the dataset, we generated dense point cloud and applied filtering manually for removing noise and outlier in the crater surface due to the effects of cloud and gases in the fissure.

\subsection{Photogrammetric Processing}

We use Agisoft Photoscan Pro software to generate 3D point clouds, DEM and orthophoto of Mt. Agung lava dome. The workflow consists several processing steps. In the first step, the algorithms detect and match the feature points in different camera perspectives by using Scale Invariant Feature Transform (SIFT) algorithms. Then, reconstruct 3D scene structure as well as solving the intrinsic and extrinsic orientation parameters of the camera and generating a sparse point cloud through SfM (Carrivick, et al., 2016). The photos were aligned by using bundle adjustment procedure based on cameras' initial locations and a sparse cloud of tie points with similar appearances in adjacent photos. Scene geometry is incrementally triangulated, resulting in a three-dimensional tie point between adjacent photos. Finally, using MVS dense image matching algorithm to produce $3 \mathrm{D}$ dense point cloud.

PhotoscanPro software is adopted to accomplish SfM-MVS algorithm, produce 3D dense point clouds and generate DSM/orthophoto data. This kind of data are used to analyse lava dome changes and to identify morphology at lava dome surface.

\subsection{Methodology of analyses lava dome change}

To calculate the difference between two data set, we apply cloud to cloud comparison $(\mathrm{C} 2 \mathrm{C})$ algorithm, a function to compute the difference of lava dome base of two data set by using Cloud Compare software. This method is a direct, simple and fast 3D comparison method of point clouds even though it deal with large point clouds and does not need of gridding or meshing while processing (Montaut, et al., 2005). Figure 6 shows the cloud to cloud distance based on the closest point distance. Each point cloud is characterized by a roughness $\left(\sigma_{1}\right.$ and $\left.\sigma_{2}\right)$, which is a combination of instrumented and related noise and surface roughness. $S_{1}$ is the reference surface that had been displaced along the local normal of $\mathrm{S}_{1}$ by true distance $\mathrm{L}_{\mathrm{t}}$. The distance was calculated for each point of $S_{2}$ (Lague, et al., 2013).

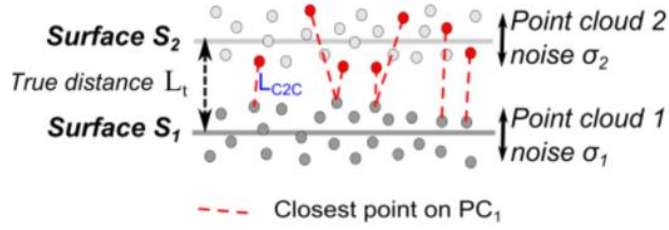

Figure 6. Simplest cloud-to-cloud distance based on the closest point distance (Lague, et al., 2013)

In order to apply this algorithm, we initially defined the UAV data on 19 Oct as the master and the one on 21 Oct as the slave. After the datasets were co-registered, this is an effective way of identifying difference between two point clouds (Lague, et al., 2013). The cloud-to-cloud distance therefore indicates the surface change of lava dome area in 3D. We also analyse the surface changes by comparing the DSM and surface profiles. Since it was unlikely to acquire GPS field data for evaluation during high volcanic activity, we used InSAR Sentinel 1A data to validate the result performed by the UAV.

\subsection{Sentinel 1A Data}

Sentinel 1A satellite data were used for evaluating the result from the UAV. We tried to find its data acquisition date as close as possible to the UAV data. After that, a pair of Sentinel 1A images along with descending path on 15 Oct and 27 Oct whose spatial baseline is $62.14 \mathrm{~m}$ is used for comparisons. The sentinel-1A descending and ascending data are feasible for evaluating the deformation pattern, as demonstrated by Bountzouklis (2016) in Santorini Greece volcano. The result demonstrated new possibilities for monitoring applications, which required continuous observation and measurements such as volcanoes, critical structures, floods, earthquakes and other natural hazards.

In this study, we estimate the surface changes and ground displacement by applying differential interferometric SAR (DinSAR) on two sentinel-1A images taken near the UAV acquisition dates. We use an open-source radar interferometry software, i.e. Generic Mapping Tools Synthetic Aperture Radar (GMTSAR), to calculate the Line of Sight (LoS) displacements as well as the azimuth and ground displacement. According to the general rule, Synthetic Aperture Radar Interferometry was a microwave remote sensing technique useful in detecting land surface deformations with high accuracy (from centimeter to millimeter accuracy) (Senturk, et al., 2016). InSAR can produce images of ground deformation more than hundreds of square kilometres without requiring instruments on the ground.

DinSAR processing have several steps: converting the radar image and orbital information into general format, co-registering two radar images, mapping topography into phase and making complex interferogram images, post-processing based on Generic Mapping Tools (GMT) that filter the interferograms and builds interferometric products of phase, amplitude and coherence. SNAPHU software is used to unwrap the process and LoS displacement in both image coordinates and geographic coordinates. SNAPHU is an implementation of the Statisticalcost, Network-flow Algorithm for Phase Unwrapping. This algorithm poses phase unwrapping as a maximum a posteriori probability (MAP) estimation problem, the objective of which is to compute the most likely unwrapped solution given the observable input data (Chen \& Zebker, 2002). 


\section{RESULT AND DISCUSSION}

\subsection{Image Quality}

As shown in Figure 7, we have a clear ortho-image of 21 Oct because it was acquired at noontime, but more cloud cover at the north-west part of the lava dome. In the meantime, on 19 Oct, the generated ortho-image has more shadows (Figure 8) since it was acquired in the afternoon, i.e. 5PM. Furthermore, in both data set, we find many volcanic gas plumes at the centre, thereby reducing the image quality.

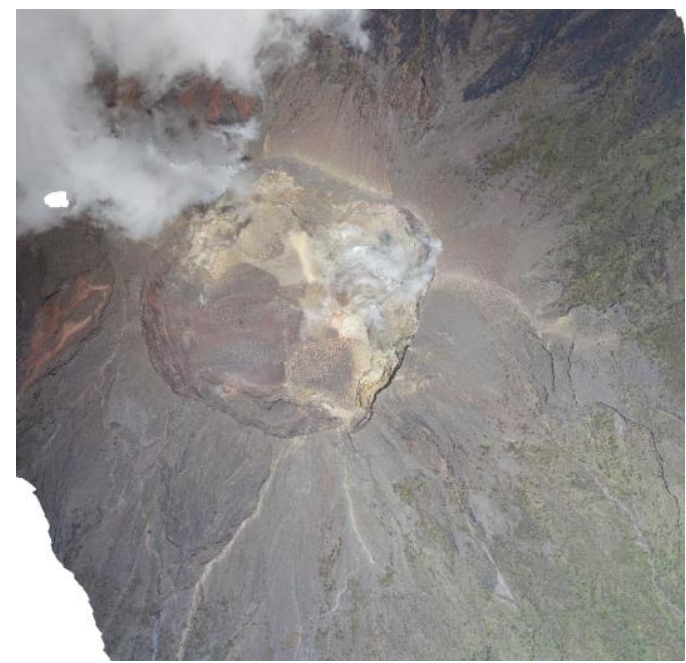

Figure 7. Ortho-image of 21 Oct 2017

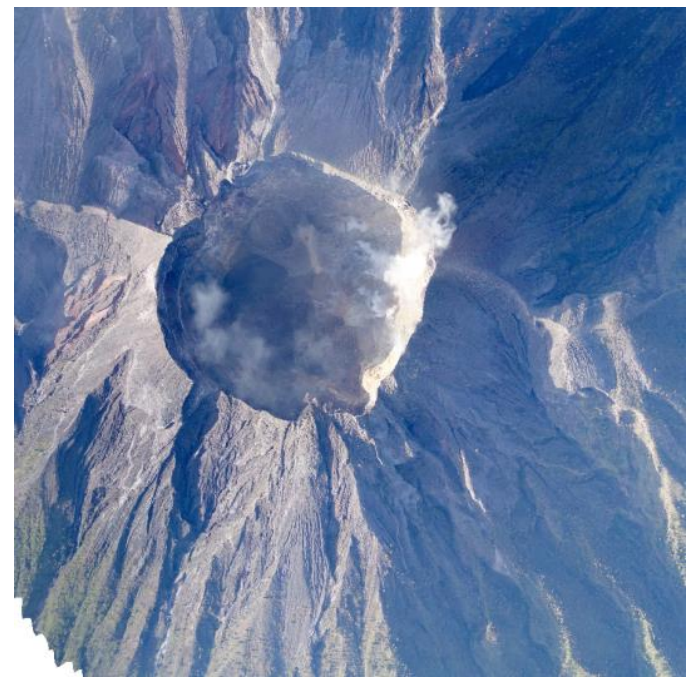

Figure 8. Ortho-image of 19 Oct 2017

\subsection{Registration of two data set}

Two data sets must be well co-registered before applying the $\mathrm{C} 2 \mathrm{C}$ algorithms. We marked several registration control points (RCP) that are correspondents between two data set. We use 14 postmarking RCPs well distributed at the surrounding of the crater. Since we have no on-site GPS measurement, this postmarking RCPs are very important to co-register these two data sets. From the error estimates report, we get residual RMS errors at $\mathrm{X}, \mathrm{Y}$, and $\mathrm{Z}$ directions with $0.37 \mathrm{~m}, 0.44 \mathrm{~m}$ and $0.55 \mathrm{~m}$ respectively. We assume that this quality is sufficient to perform changes detection because it is less than the spatial resolution, i.e. $44.7 \mathrm{~cm}$ of of the acquired UAV image around the crater.

\subsection{Surface changes based on DEM and orthophoto}

Through photogrammetric processing, we have obtained DEM data set with a spatial resolution of $1.79 \mathrm{~m} /$ pix on 19 Oct and 0.66 $\mathrm{m} / \mathrm{pix}$ on 21 Oct. The data set on 21 Oct yields better spatial resolution of surface morphology than 19 Oct due to lower flying altitude. Both data sets allow us to identify the surface phenomena around the lava dome and create surface profile. The texture of point clouds is generated and visualized in 3D mesh model to get better detection and identification of the lava dome surface. By applying visual interpretation of the 3D mesh, we conclude that there is no significant morphological changes between these two data set, as shown in Figure 9. The reason is that the time interval of two data acquisition dates is indeed quite short, i.e. 2 days. This indicates that the activity of magma at that time was somewhat low, so that there was no topographic and morphological change in the lava dome surface.

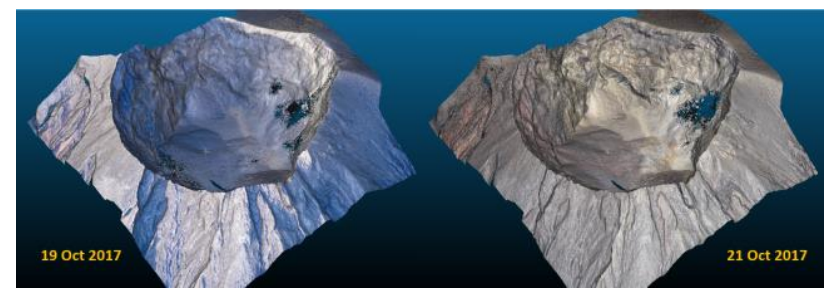

Figure 9. 3D mesh lava dome surface

In addition, we find two fluid areas at the crater's surface as shown in Figure 10, in NE direction (4,375.9 sq-m) and SE direction $(3,749.8 \mathrm{sq}-\mathrm{m})$. We also detect fumarole which emits steam and gases only in the eastern part and continues until the next two days at the same place. In the western part, we do not find any fumarole with gas emerged. Furthermore, we suspect that magma activity only occurs in the centre to the east side of the crater. In Figure 10.a and 10.b, the data set show the fluid and fumarole in the centre and east of the crater on 19 Oct and 21 Oct. The red lines illustrate the fluid area, whilst the blue ones denote the fumarole sources.



Figure 10.a Fluid and fumarole area appear at 19 Oct 2017

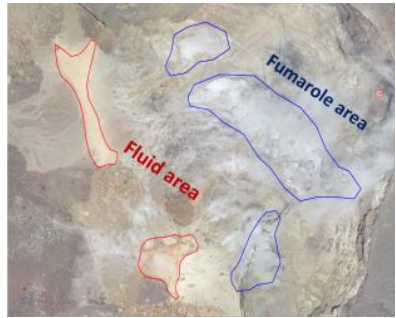

Figure 10.b Fluid and fumarole area appear at 21 Oct 2017
Based on these data, we conclude that there is no big change in the shape or area of fluids and fumaroles. This also indicates that magma activity tends to be stable at that time. For better understanding and quantifying the changes, we create a shaded relief (Figure 11.a and 11.b) and elevation cross section between two data set of DTMs. In general, the topographic surface in the lava dome between two data set have similar pattern. However, in the South-Western part we find a significant difference of topographic surface, as shown in the yellow line area (Figure 11a and $11 \mathrm{~b}$ ), but it occurs because cloud and gases cover around these areas. 

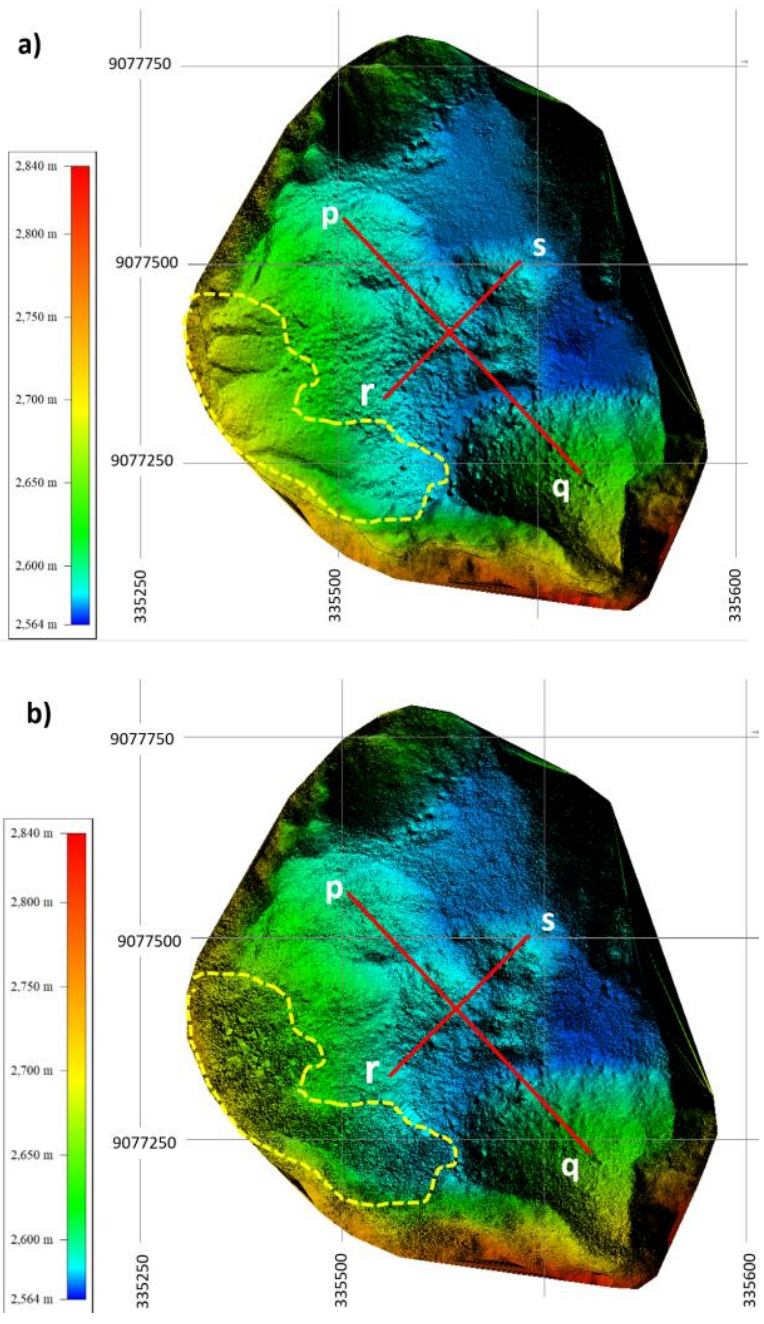

c)

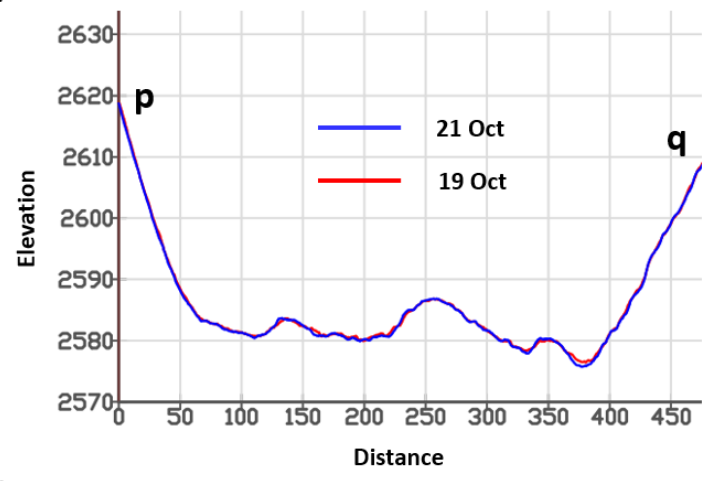

d)

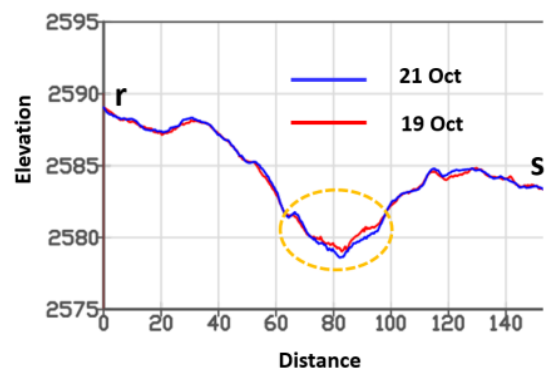

Figure 11. (a) shaded relief of the 21 Oct and (b) 19 Oct Digital Elevation Model. (c) cross-section at NW-SE direction. (d) cross-section at SW-NE direction.
In order to quantify the changes of elevation, we use cross section profile to identify the height difference between two surfaces. A cross section profile of line p-q (Figure 11.c) shows a detailed surface profile from NW to SE direction. The red colour shows the DEM surface on 19 Oct and the blue one denotes the surface on 21 Oct. Both lines have similar pattern with smaller height difference. It shows that no significant change has found in this profile. However, in the SW to NE direction profile, as shown in the line r-s (Figure 11.d) has similar surface pattern, but in some parts of the valley (yellow circle) there is a slightly difference in height.

\subsection{Calculation difference on two data set of point clouds}

We also calculate the distance between two point clouds data to better understand the surface changes in the whole area. Figure 12 shows the coloured dataset according to scalar field base on $\mathrm{C} 2 \mathrm{C}$ algorithms. The red colour indicates maximum distance values of $2.55 \mathrm{~m}$, whereas the blue one has the lowest distance of $0.37 \mathrm{~cm}$. The average distance is $2.27 \mathrm{~cm}$. Based on this result, we noticed that no significant surface change was found around the lava dome surface. It shows that the UAV photogrammetry is capable to detecting surface changes in the centimeter fraction.

The largest distance illustrated by red colour occurs at locations where gases and clouds occurred. Although filtering and cleaning processes have been done, it still contains point clouds noise. Thus, this high distance does not indicate morphologic changes of the lava dome surface, but it is caused by influence of clouds and gases that appear in the crater.

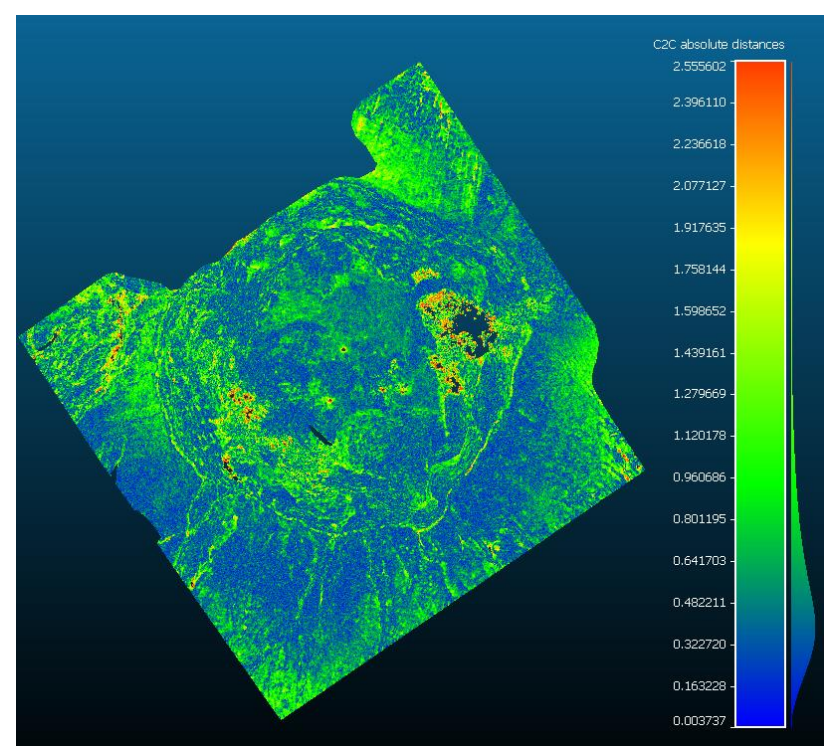

Figure 12. Point clouds comparison (distance) between Oct 19 and Oct 21

\subsection{Interferometric result from Sentinel 1A data}

SAR satellites use microwaves to detect the displacement on the surface of earth. The sensor use signal in microwave wavelengths from $1 \mathrm{~cm}$ to $1 \mathrm{~m}$. We use Sentinel-1A, which use C-band with a wavelength of $6 \mathrm{~cm}$. Standard differential SAR interferometry is applied to estimate the deformation surface. Sentinel 1 interferogram is generated by processing descending imagepaired that covers at Mount Agung. The interferogram is created by subtracting the phase differences from the master image with the slave one, resulting in color fringes to depict the distance the ground movement (Moore, 2016). The full color fringe is called 
the interferometric phase. Figure 13 shows the interferometric result, there are two fringes surrounding the Mt. Agung volcano. This difference is depicted on an InSAR image as color fringes. One fringe is one cycle of the spectrum colors from purple to red. The displacement represented by one color fringe is half the wavelength of the C-band, i.e. $3 \mathrm{~cm}$. The total displacement is calculated by counting the number of color fringes multiplied by the scale, approximately 2 fringes, so that the displacement is around $6 \mathrm{~cm}$.

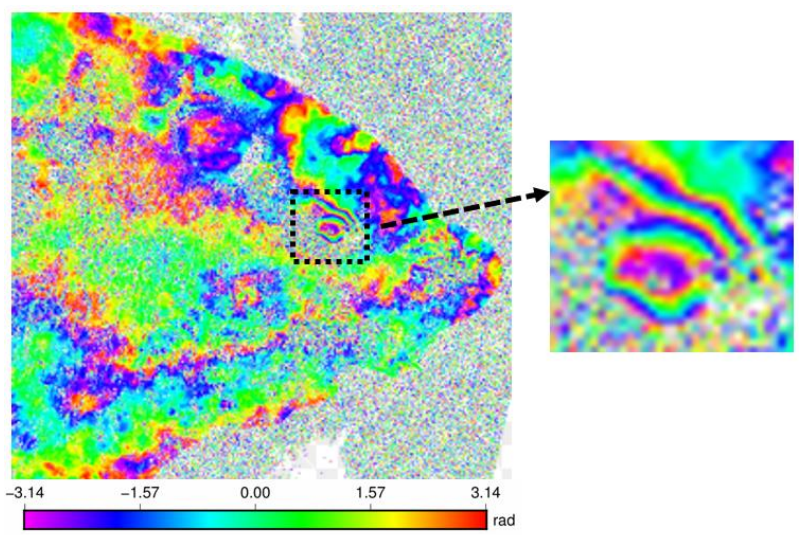

Figure 13. Sentinel 1A interferogram result

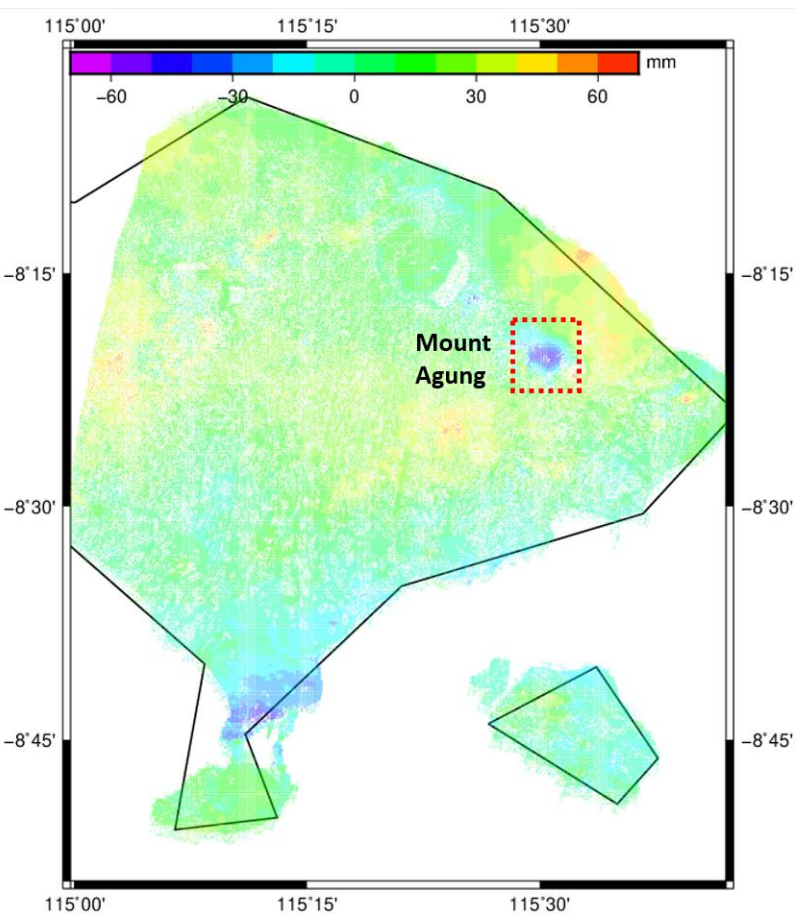

Figure 14. Line of Sight $(\operatorname{LoS})$ displacements

Unwrapped interferograms show total displacement of deformation in the satellite's LoS. An unwrapped interferogram was created by adding the fringes together from the wrapped interferogram. Based on LoS calculation, as shown in Figure 14, the unwrapped pattern at the mountain area reaches a maximal LoS deformation. The vertical displacement with maximum value is close to $6 \mathrm{~cm}$, agreeing with the findings of the wrapped interferogram. It means that the ground movement has moved away from the satellite indicating the distance between the ground and the satellite has increased.

\section{CONCLUSIONS}

We would like to state that this is the first data of UAV photogrammetry performed in Mount Agung before its eruption in 2017. This research, therefore, demonstrates a potential method to detect lava dome changes during high-level of volcanic activity with photogrammetric methods by using UAV images. The UAV photogrammetry methods make it possible to produce high resolution DEM efficiently and safely with suitable accuracy during high volcanic activity. Moreover, it can also detect the surface changes in the centimeter fraction.

The lava dome changes, which are represented in the form of topographic surface as well as other natural phenomena such as the emergence of fluids and fumaroles, are very necessary to be monitored regularly and continually to depict the lava dome pattern. This is therefore useful to hazard assessment purposes and decision makers to plan suitable emergency responses.

\section{ACKNOWLEDGEMENTS}

We would like to thank the Indonesian National Disaster Management Authority, especially Dr. Sutopo Poerwo Nugroho and Dian Oktiari for giving us authority to the data acquisition. Also for Head of Department of Geodetic Engineering, Dr. Priyono Nugroho and DERU (Disaster Response Unit) UGM for supporting our mission. In addition, we acknowledge for Wahyu Widianto and Budi Wahyono for contributing fieldwork in 2017. Finally, we would like to thank all the reviewers for their constructive suggestion to improve the article.

\section{REFERENCES}

Beni, E. D., Cantarero, M. \& Messina, A., 2019. UAVs for volcano monitoring: A new approach applied on an active lava. Journal of Volcanology and Geothermal Research 369 (2019) 250-262.

Bountzouklis, C., 2016. Monitoring of Santorini (Greece) volcano during post-unrest period (2014-2016) with Interferometric Time series of Sentinel-1A, s.1.: Master degree thesis, Department of Physical Geography and Ecosystem Science, Lund University.

Calder, E. S., Lavallee, Y., Kendrick, J. E. \& Bernstein, M., 2015. The Encyclopedia of Volcanoes - Lava Dome Eruptions. s.l.:http://dx.doi.org/10.1016/B978-0-12-385938-9.00018-3.

Carrivick, J.L., Smith, M.W., Quincey, D.J, 2016. Structure from Motion in the Geosciences. s.l.:John Wiley \& Sons, Ltd, United Kingdom.

Chen, W. \& Zebker, H. A., 2002. Phase Unwrapping for Large SAR Interferograms: Statistical Segmentation and Generalized Network Models. IEEE Transactions on Geoscience and Remote Sensing, Vol. 40, No. 8.

Darmawan, H. et al., 2017. Morphological and structural changes at the Merapi lava dome monitored in 2012-15 using unmanned aerial vehicles (UAVs). Journal of Volcanology and Geothermal Research 349 (2018) 256-267.

Girardeau-Montaut, D., Roux, M., Marc, R., Thibault, G, 2005. Change Detection on Points Cloud Data Acquired With a Ground Laser Scanner. s.1., s.n., pp. 30-35. 
J.J. Major, D. Dzurisin, S.P. Schilling, M.P. Poland, 2009. Monitoring lava-dome growth during the 2004-2008 Mount St. Helens, Washington,. Earth and Planetary Science Letters 286 (2009) 243-254.

Lague, D., Brodu, N. \& Leroux, J., 2013. Accurate 3D comparison of complex topography. ISPRS J. Photogramm. Remote Sens. 82, p. 10-26.

Moore, S., 2016. InSAR, Interferometric Synthetic Aperture Radar: A remote sensing tool for measuring Earth's surface deformation. s.l., UNAVCO Education and Community Engagement Program.

Nicolas R. Turner, Ryan L. Perroy, Ken Hon, 2017. Lava flow hazard prediction and monitoring with UAS: a case study from the2014-2015 Pāhoa lava flow crisis, Hawai'i. Journal of Applied Volcanology (2017) 6:17, pp. DOI 10.1186/s13617-0170068-.

PVMBG, 2017. Press Release PVBMG (Centre of Volcanology and Geological Hazard Mitigation), s.l.: https://magma.vsi.esdm.go.id/press/view.php?id=95.

Senturk, S., Cakir, Z. \& Ustundag, B. B., 2016. The potential of Sentinel-IA interferometric SAR data in monitoring of surface subsidence caused by overdrafting groundwater in agricultural areas. s.l., 2016 5th International Conference on Agrogeoinformatics (Agro-geoinformatics). 